\title{
Intraoperative image-guided spinal navigation: technical pitfalls and their avoidance
}

\author{
Gazanfar Rahmathulla, M.D., ${ }^{1}$ Eric W. Nottmeier, M.D., ${ }^{1,2}$ Stephen M. Pirris, M.D., ${ }^{1}$ \\ H. Gordon Deen, M.D., ${ }^{1}$ and Mark A. Pichelmann, M.D. ${ }^{1}$ \\ ${ }^{1}$ Department of Neurosurgery, Mayo Clinic; and ${ }^{2}$ St. Vincent's Spine and Brain Institute, Jacksonville, Florida
}

\begin{abstract}
Spinal instrumentation has made significant advances in the last two decades, with transpedicular constructs now widely used in spinal fixation. Pedicle screw constructs are routinely used in thoracolumbar-instrumented fusions, and in recent years, the cervical spine as well. Three-column fixations with pedicle screws provide the most rigid form of posterior stabilization. Surgical landmarks and fluoroscopy have been used routinely for pedicle screw insertion, but a number of studies reveal inaccuracies in placement using these conventional techniques (ranging from $10 \%$ to $50 \%$ ). The ability to combine $3 \mathrm{D}$ imaging with intraoperative navigation systems has improved the accuracy and safety of pedicle screw placement, especially in more complex spinal deformities. However, in the authors' experience with image guidance in more than 1500 cases, several potential pitfalls have been identified while using intraoperative spinal navigation that could lead to suboptimal results. This article summarizes the authors' experience with these various pitfalls using spinal navigation, and gives practical tips on their avoidance and management. (http://thejns.org/doi/abs/10.3171/2014.1.FOCUS13516)
\end{abstract}

KEY WORDS $\quad$ intraoperative spinal navigation $\quad$ pitfall $\bullet \quad$ avoidance
image guidance

$\mathrm{T}$ RANSPEDICULAR instrumentation has become the favored tool of the spine surgeon for a wide variety of spinal stabilization procedures. ${ }^{26,54}$ The goals of any spinal procedure may include decompressing neural elements and preventing or correcting deformity if necessary, using spinal fixation that results in earlier mobilization and rehabilitation. Using standard insertion techniques, the rate of misplaced pedicle screws ranges from $14 \%$ to $55 \%$, with as many as $7 \%$ of these misplaced screws resulting in neurological injuries.,28-30,71 Spinal navigation was introduced in 1995 with a goal of improving the accuracy of pedicle screw insertion and thereby minimizing the risk of neurovascular injuries. As a result, there has been a substantial increase in the use of spinal navigation with ever-improving image capture devices and registration platforms. ${ }^{38}$ The advantages of using spinal navigation for accurately placing pedicle screws have been reported in a multitude of studies. ${ }^{10,13,35,43}$

In a cadaveric study by Weinstein et al., ${ }^{73}$ pedicle screws violated the cortex in $21 \%$ of the specimens when inserted using anatomical landmarks. A number of other studies have described pedicle violations ranging from $10 \%$ to $50 \%$ in the cervical and thoracic spine, where the size, shape, and orientation of these pedicles makes it more challenging to insert pedicle screws when guided by anatomy or fluoroscopy. ${ }^{4,16,24,32,73}$ Other authors have found that freehand placement of pedicle screws may be safe in very experienced hands. The use of image guidance has been reported to consistently reduce pedicle breaches

Abbreviation used in this paper: $\mathrm{OR}=$ operating room. to less than $5 \%$ in a number of published studies. ${ }^{21,22,53,68}$ Shin et al. have shown a decrease in pedicle perforation rates from $15 \%$ in nonnavigated screws to $6 \%$ in navigated pedicle-screw insertions. ${ }^{60}$ These findings have resulted in the increased use of image guidance for spinal fusion. However, spinal navigation should be thought of as an adjunct to thorough knowledge of spinal anatomy, and not be used as a substitute for it. It is therefore critical to recognize the limitations of this technology.

The purpose of this article is to review the most recent literature and discuss various pitfalls in the use of intraoperative spinal navigation, thereby providing insights into avoiding common errors and their associated complications during spinal fusion procedures.

\section{Preliminary Concepts}

The most commonly used forms of image-guided navigation in spine surgery presently include 2D images, in which a fluoroscope or plain radiography is used, and 3D navigation, making use of cone-beam CT or CT scans. The 3D systems provide projections of the operative field and instruments with imaging in 3 axes. ${ }^{11}$ The principle goal is to track surgical instruments and anatomy in the operative field relative to a registered reference point. ${ }^{20}$ The most commonly used method is by optical tracking using cameras that project and detect reflected infrared light from reflecting spheres or light-emitting diodes. This technology enables the surgeon to navigate the patient's spine anatomy using a visual image that shows the position of 
tracked instruments relative to the surgical field. ${ }^{60}$ Various methods used to register the surgical space with image guidance have included material fiducials, anatomical fiducials, and surface-based registration techniques. The use of material fiducials in spine surgery had drawbacks because it required the attachment of fiducials prior to surgery, resulting in inaccuracy when used with spinal navigation, and is not currently used. ${ }^{8,23}$ Anatomical fiducials required certain anatomically accessible targets to be exactly identified by the surgeon, and then these points in the intraoperative space were matched to CT-based imaging. However, this process, known as paired-point matching, was the least accurate because the surgeon had to identify the exact anatomical location, which remains a difficult task. A variant of the anatomical registration includes surface-based pointpairing techniques. Once registration has occurred, various instruments with reference markers can be appropriately localized in the surgical field, and the tool tips and projections in the axial, coronal, and sagittal planes are computed and projected for the surgeon. A number of possible sources from which errors arise have been documented in early publications on spinal navigation and image-guided registration accuracy. ${ }^{17,63}$ The introduction of cone-beam CT brought about a change by enabling intraoperative registration of the surgical space to take place following surgical exposure and delineation of bone anatomy.

The 2D imaging systems use anteroposterior and lateral fluoroscopic images obtained during the case and combine them with the preoperative CT images on the navigation system. The advantages of $2 \mathrm{D}$-based systems were speed, decreased radiation exposure, and ease of use, but these systems were not as accurate as the next generation of 3D-guided navigation systems. ${ }^{25,33,65}$ The introduction of cone-beam CT enabled multiple fluoroscopic image acquisition by a device that rotated isocentrically around the patient. The images are reconstructed into a cone-beam CT scan that can be used for navigation once it is transferred to an image-guided system. As the reference arc is tracked with the patient imaging, the computer-generated 3D image of the patient's operative field is already registered and ready for use with navigation. Advantages with the use of this technology include the ability to image multiple levels in a single sequence, imaging accuracy in patients who had undergone prior spine surgeries at the same levels, decreased radiation exposure to the operating room (OR) staff, improved accuracy because the patient's anatomy is registered in the surgical position, and portability of the system so it can be easily transported between ORs. ${ }^{39-41}$ The present cone-beam CT-based systems include the Arcadis Orbic 3D isocentric C-arm (Siemens AG), the Ziehm Vision FD Vario 3D (Ziehm), and the $\mathrm{O}$-arm (Medtronic). In addition to these systems, more recent 32-slice mobile intraoperative CT scan platforms that can be integrated with navigation systems for use in spinal navigation have been released and include the Airo (BrainLAB) and BodyTom (NeuroLogica Corp.).

The benefits of spinal navigation have been described in minimally invasive surgical procedures, as well as in the treatment of complex deformities, tumor, and trauma of the spine when the anatomy is distorted and visual and tactile landmarks are not readily available to the spine surgeon. ${ }^{15}$

\section{Literature Review and Author Experience}

For this review, a PubMed-based literature search was performed to identify any published studies regarding the errors, technical pitfalls, and complications when using spinal navigation pedicle-screw insertions in the cervical and thoracolumbar spine. The keywords used while searching the database included "spinal navigation pitfalls" and "navigation complications." There have been numerous articles published on the efficacy and advantages of intraoperative navigation utilization, but to date no publications have addressed the technical issues and pitfalls that occur while using intraoperative navigation. The intraoperative navigation pitfalls could eventually lead to a loss of OR time, prolonged anesthesia, blood loss, intraoperative pedicle screw errors, and inadvertent neurological complications. Poor planning in the pre- and intraoperative stages will obviate any advantage of an intraoperative navigation system.

At our institution we obtained the O-arm (Medtronic) combined with Stealth navigation in April 2008, prior to which time the authors had used alternative systems (BrainLab, Iso-C) for image-guided spine surgery. The authors in this paper have a combined experience of having used image-guided navigation for spine surgery in more than 1500 cases. Based on this vast experience with image-guided spine surgery, we have attempted to classify and categorize these pitfalls with the use of intraoperative spinal navigation. We will describe these pitfalls along with an illustrative case, showing how to avoid these problems. The most important factor remains the time and technical nuances with spinal image guidance that can be further subcategorized into preoperative, intraoperative, and postoperative considerations. The inability to develop a smooth workflow and plan ahead decreases the efficiency of the operating team. To simplify any spinal procedure we have implemented a checklist (Fig. 1) depending on the region where the surgery is to be performed, the type of procedure, and OR requirements. This measure helps to keep the OR staff prepared for the procedure and all the equipment appropriately arranged in the work environment on the day of surgery. Our OR setup with the arrangement of various equipment has been outlined (Fig. 2); the implementation of this setup minimizes confusion for any spinal case using intraoperative navigation.

\section{Preoperative Considerations}

Prior to starting a spinal fusion procedure, various operative considerations such as positioning, neuromonitoring, and equipment require appropriate selection. The surgical team is responsible for dissemination of information to OR personnel, who will in turn organize the OR.

\section{Obese Patients}

Preoperative patient factors include the potential difficulty of performing adequate imaging on obese and morbidly obese patients. The increased soft tissue in patients with morbid obesity ${ }^{36,72}$ may create difficulty with positioning, beam penetration, and the ability to maneu- 
Pitfalls in image-guided spinal navigation

Region of surgery:

- Cervical

- Thoracic

- Thoraco-lumbar

- Lumbar

- Lumbo-sacral

\section{Operating table}

- Radiolucent Wilson frame

- Regular OR table

- Jackson table (decide on short vs. long board requirement)

Patient position

- Supine

- Prone

- Lateral

- Sitting

- Partial lateral

- Additional requirements (Gel rolls / hip pads / blanket rolls)

- Arm position (tucked by the side / flexed \& upwards)

Image guidance \& fluoroscopy

- O-arm and Stealth (our Institute)

- Intraoperative fluoroscopy \& navigation

- BrainLab

- Stryker

Head fixation

- Cervical sling

- Mayfield head frame

- Gardner Wells tongs

Intraoperative neuromonitoring: SSEPs/MEPs/EMGs

Instrumentation

- Special requirements (navigation attachments)

- Interbody cage

- Iliac crest harvesting tools

- Others

Headlights / loupes/microscope

Intermittent pneumatic compression device on legs

Appropriate instruments for surgery

Local hemostatic agents / pulse irrigation

Body warming system

Intraoperative cell salvage machine

FIG. 1. Institutional preoperative workflow and equipment checklist used prior to any spine surgery. EMG = electromyography; MEP = motor evoked potential; SSEP = somatosensory evoked potential.

ver imaging devices around the patients. This results in poorer quality images that can make the registration process inaccurate, as well making the images difficult to use during surgery.

\section{Surgical Learning Curves}

Surgeon learning curves when new technology emerges have been reported in robotic and laparoscopic surgery ${ }^{34,37}$ For spine surgery, the learning curve for adopting 
G. Rahmathulla et al.

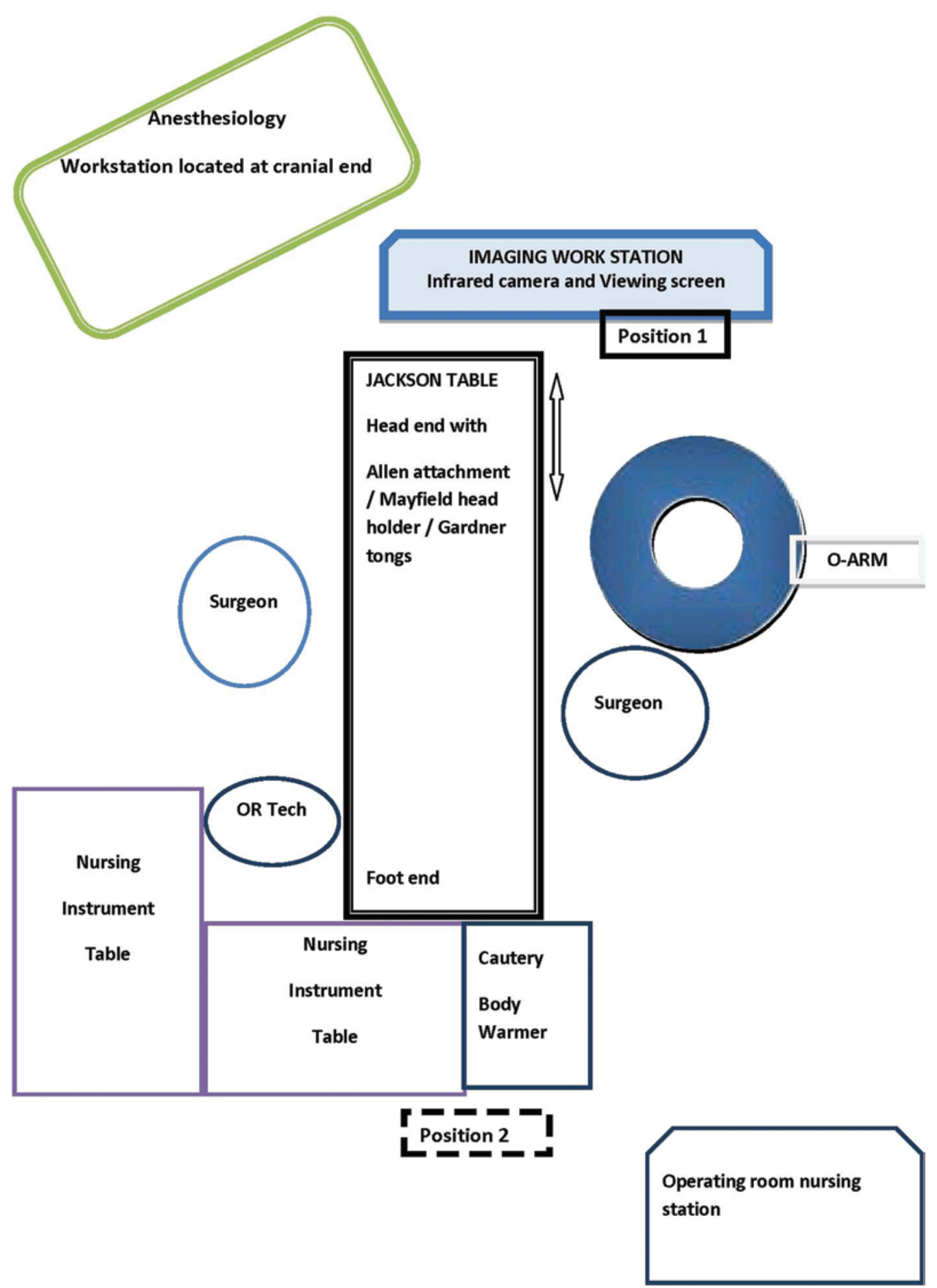

Fig. 2. Linear diagram (not to scale) outlining the OR setup for a spinal fusion case with the image guidance camera and viewing screen placed cranially (Position 1). The O-arm can be moved in and out of position depending on the case and location of imaging required. Certain cases require the camera and screen to be placed at the foot end of the table (Position 2) to obtain a clear line of sight and images for navigation.

image-guided technology has been reported by Bai et al. ${ }^{6}$ and Sasso et al..$^{56}$ The components of the learning curve include the ability to direct instruments based on imaging visualized on a screen, the ability to replicate in-line maneuvers while placing instrumentation, as well as adopting and developing proper technique while using image-guid- ed technology. ${ }^{39}$ The ability of surgeons to adapt to the use of this technology may depend on a generation of surgeons who grew up playing video games. Rosser et al. was able to correlate faster completion and reduced errors in laparoscopic surgeries when the surgeons had a background of more than 3 hours per week of video game play. ${ }^{55}$ 


\section{Surgical Table Selection}

Appropriate selection of an OR surgical table for image guidance is important. Modern spine surgical ORs have a variety of equipment at the surgeon's disposal. Different operating tables have advantages and disadvantages for surgical positioning, exposure, and intraoperative imaging. The dimensions and designs of regular OR tables may hinder one's ability to perform imaging with modern cone-beam CT-based imaging systems. Two-dimensional fluoroscopy is compatible with many OR tables as long as the patient is positioned appropriately. The Jackson table enables greater deformity correction and correction of alignment along the entire neuraxis, making it ideal for complex spinal fusions. The design of the O-arm allows it to work ideally with the Jackson table, which does not have a base obstructing movement along the long axis of the patient and table. The Jackson table enables the O-arm to be positioned along any level of the spinal axis. The table is well designed for imaging purposes, with its core structure such that the table has minimal radiodense metal resulting in minimal radiographic artifact.

\section{Sterile Draping}

Sterile draping is a consideration. Current draping of the fluoroscope is simple and standardized such that the OR staff is able to perform this seamlessly. However, the sterile cover for $\mathrm{O}$-arm use remains cumbersome, at times getting caught between the shields. This has occurred during our initial learning curve with spinal navigation using the $\mathrm{O}$-arm. Once the drape is caught, the failsafe prevents it from opening in an automated manner and manual maneuvers have to be used to open out the O-arm (Fig. 3). In our experience, an alternate draping of the patient in a $360^{\circ}$ circumferential manner is more efficient and avoids problems while the $\mathrm{O}$-arm opens and closes around the patient and operating table (Fig. 4). This method of draping could also be adopted for the new intraoperative CT scanners as well.

\section{Registration Process}

The registration process following patient positioning is crucial. Inaccurate registration with the use of image guidance and computer-assisted navigation potentially has multiple sources of error. This necessitates frequent validation and accuracy assessment on a continuous basis. Early computer-based navigation systems required registration of preoperative images with the surgical intraoperative space. The margin of error for insertion of a pedicle screw depends mainly on the size of the pedicle, size of the screw, and distance to the isthmus or narrowest point on the pedicle. Rampersaud et al. evaluated error margins and demonstrated very small tolerances, with less than $1 \mathrm{~mm}$ permissible for translation and less than $5^{\circ}$ for rotational changes in the cervical, thoracic, and thoracolumbar junctions. ${ }^{51}$ Glossop et al. demonstrated a clinical utility error range of 2-3 $\mathrm{mm}$ of translation and $4^{\circ}-7^{\circ}$ of rotation using image-guided navigation..$^{14}$

Intraoperative image acquisition and registration should therefore be performed after surgical access is completed. This avoids angular and translational movements that may alter the image registration. With con- ventional open midline access, image acquisition and registration should be performed after completing the approach to eliminate motion-related inaccuracy. In contrast, percutaneous minimally invasive instrumentation may begin immediately after the intraoperative registration procedure without prior anatomical landmark dissection, as significant manipulation of the surgical field and landmarks do not occur in these procedures. ${ }^{59}$

Errors during image registration can occur. Patients undergoing surgery have 2 body warmers to prevent hypothermia, 1 placed over the upper body and the other over the lower body. During image acquisition for registration with cone-beam CT scans, the upper body warmer has to be turned off to avoid increasing imaging artifacts and creating registration errors. Additionally, movements during respiration and image acquisition can cause significant changes and inaccuracies with registration. The anesthesiologist has to specifically hold the patient's respiration during this step, minimizing errors secondary to motion artifact. Image acquisition is also performed after the dissection, and afterward the deep retractors are left in situ, especially for mobile cervical spine segments. The surgeon should avoid changing the position of the table (Trendelenburg position or the reverse) and attempt to avoid any potential movements with instruments that may cause distortion of anatomy, such as drilling and tapping all holes prior to instrumentation.

There is potential inaccuracy with increasing distance of screw placement from the reference arc. Quiñones-Hinojosa et al. analyzed 3D fluoroscopy-identified errors of accuracy at different distances from the reference arc and different time points when used in lumbar spine fusion surgery. ${ }^{47}$ They identified increasing distance from the reference arc and increased duration of surgery as the main factors, with inaccuracy of $3 \mathrm{~mm}$ in $7 \%$ of the patients when surgery was 3 levels away from the reference arc, and inaccuracy of $3 \mathrm{~mm}$ in $17 \%$ about 1 hour into surgery. Scheufler et al. performed pedicle screw instrumentation using a single-registration sequence in 32 (91.4\%) of their 35 patients, with as many as 12 vertebrae instrumented after a single registration sequence. They identified a statistically insignificant increase in misplaced screws by about $2 \mathrm{~mm}$ at distances 10 segments between the instrumented segment and reference arc. ${ }^{58}$ Interestingly, Holly et al. ${ }^{18}$ demonstrated that navigation error is an interaction between technology and human factors, remaining the same independent of registration techniques. ${ }^{67}$

\section{Considerations Based on the Region of the Surgical Spine}

\section{Cervical Spine}

For posterior cervical spine surgery (occipitocervical fusions), the reference arc can be placed on the Mayfield headholder, ${ }^{44}$ with some surgeons preferring the arc on the most distal spinous process exposed in the surgical field. Additionally, to minimize intersegmental movement in the upper cervical spine, imaging should be performed following dissection up to the bone anatomy and placement of retractors to minimize movement after image acquisition and registration. Drilling of pilot holes must be completed 


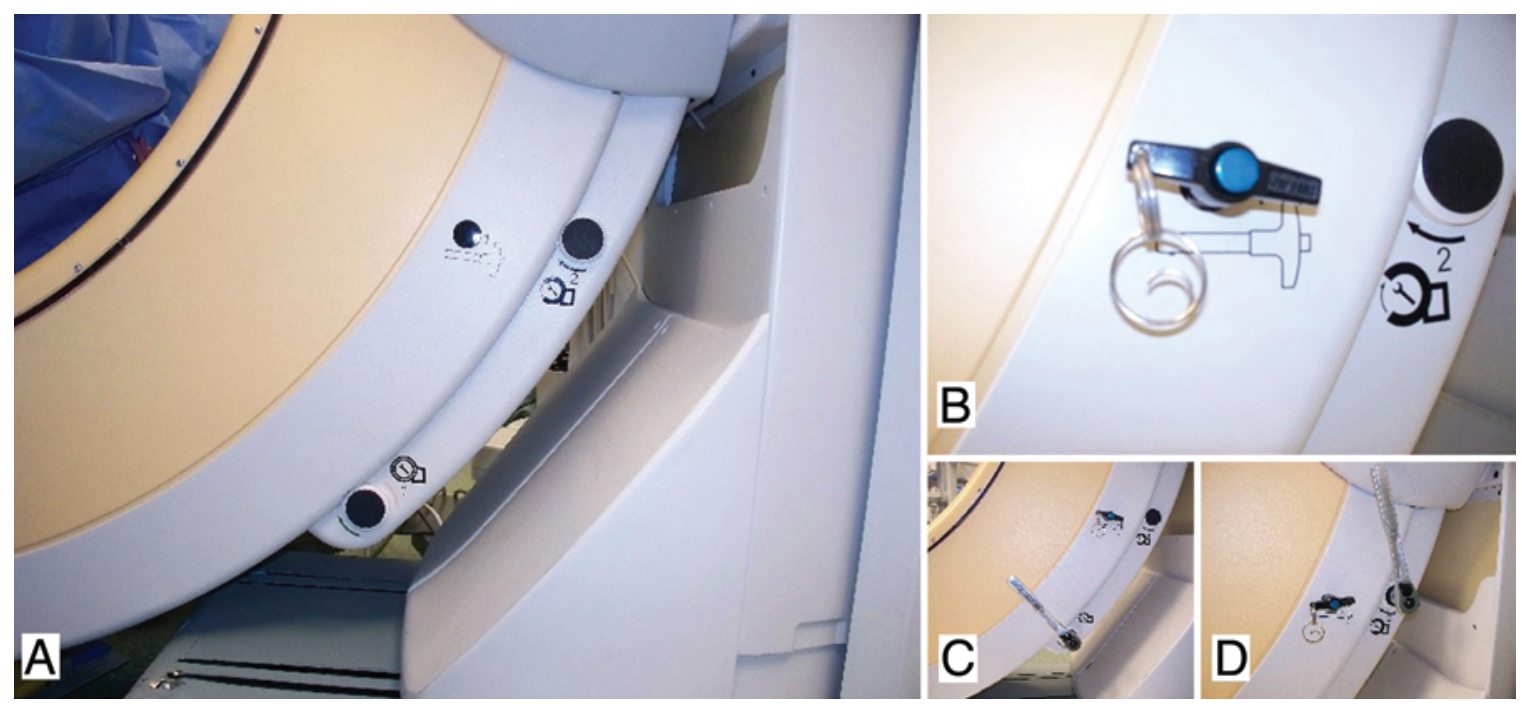

FIG. 3. Photographs demonstrating manually opening the O-arm. A: A sequence of steps at 3 points, all of which are visible in A, is required. B: Inserting a key into the appropriate slot is the first step. C: Inserting a manual driver into slot 1 enables closing of the gantry. D: Inserting the driver into slot 2 enables manual opening of the gantry in case of emergency or nonfunctioning automated mechanisms.

prior to tapping and placing screws, the patient's respiration must be held (by the anesthesiologist) during image acquisition, and changes in table position must be avoided. In rare cases in which image-guided navigation needs to be used for anterior cervical cases, the cranial reference arc is attached to the Mayfield headholder. ${ }^{44,46}$ Navigation is beneficial in identifying complex bone anatomy, maintaining midline orientation in rotary scoliosis, and locating the vertebral artery foramen in complex tumor cases where this structure may be involved or displaced. Key landmarks need to be marked out prior to bone removal as this segment of the spine is mobile, resulting in positional changes and distortion, with navigation becoming inaccurate after beginning spinal manipulation.

\section{Thoracic Spine}

We have found that in patients positioned for anterior and lateral approaches to the thoracic spine, the surgeon is
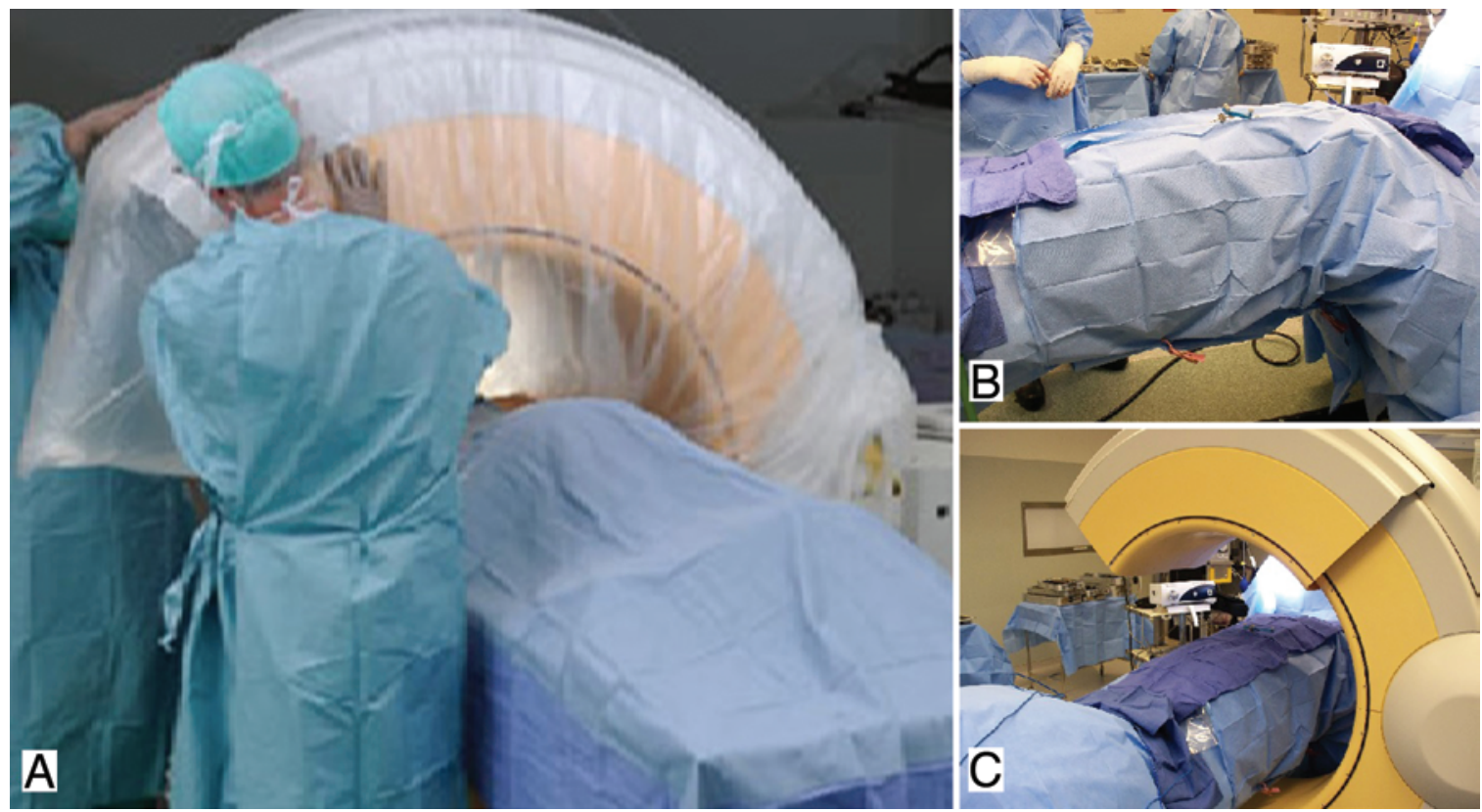

FIG. 4. Intraoperative photographs demonstrating avoidance of draping problems. A: Initial sterile tube drape that is used with the $\mathrm{O}$-arm. The drape is cumbersome and redundant due to its exaggerated dimensions to accommodate the $\mathrm{O}$-arm, which means that excessive draping would at times get stuck while the gantry tries to close and open. B: Our sterile draping technique requires filling the surgical wound with antibiotic irrigation solution and using surgical split-sheet drapes to circumferentially enclose the patient, keeping the reference arc just above the drapes. C: With gantry closure there is no contact between the patient, reference arc, and the tube. Following imaging, these drapes are removed and procedure continued. 
limited in his or her ability to place the reference arc in an ideal position near the surgical field and obtain clear images. The size and depth of the bore, patient positioning, and orientation are limiting factors for the use of fluoroscopic systems as well as cone-beam CT-based systems. In these cases, it is ideal to perform fluoroscopy-based imaging, utilizing surgical landmarks and imaging landmarks as guides for the procedure. We have found an alternative location, placing the reference arc percutaneously in the iliac crest. However, the caveat remains that the access surgeon helping in the exposure should be comfortable using a Jackson table. Ideally, use of radiolucent retractors avoids imaging artifacts, but if these are not available, standard retractors have to be removed to obtain clear images without distortion. The spine surgeon should keep in mind that navigation is useful for bone anatomy and not useful in delineating the adjacent vascular anatomy or soft-tissue structures.

\section{Lateral Thoracolumbar Surgery}

Recently there has been increasing interest and use of lateral approaches to the lumbar spine to perform interbody fusions in patients with spinal deformity, spondylosis adjacent to a previous fusion, or degenerative disc disease. Spinal navigation systems have been adapted to these procedures and the dissection, discectomy, and implant tools can be currently paired to navigation to help increase the safety and efficiency of these procedures. Navigation simplifies patient positioning, enabling patients to be easily placed laterally on a Wilson frame, on top of a flat table rather than maneuvering the operative table to perfectly align with anteroposterior and lateral fluoroscopy. The navigated dissection and discectomy tools help to confirm appropriate passage through the tissues and disc space. Preoperative planning with proper placement of the reference arc is crucial. The reference arc must be placed in a position that can be seen by the camera, close enough to the operative field to maintain accuracy, and out of the line of sight to the operative tools. We have found that placing a percutaneous reference arc into the posterior iliac crest serves better than placement into the lateral iliac crest. The lateral crest site may obscure visualization of the arc, and because of the proximity to the surgical site, interferes with the operative tools as they are placed into the disc space (Fig. 5).

\section{Intraoperative Considerations}

\section{Operating Room Setup}

Operating room setup and line-of-sight issues can lead to significant delays. Proper setup of the OR is essential for efficient implementation of spinal imaging guidance. In open spinal fusion cases, the camera is placed at the head of the OR table above the anesthesiologist, with the computer monitor placed across the OR table from the surgeon to allow the surgeon easy visualization of the monitor. In minimally invasive spinal fusion cases, in which the reference arc will be placed percutaneously on the iliac crest, the camera is placed at the foot of the bed to keep the reference arc between the camera and the working field in which the image-guided instruments will be used. All image-guided instruments are registered by the OR staff prior to the start of the case.

Additionally, the type of spinal fusion case and surgeon preferences are entered into the image-guided system. The ability to view the reference arc, and the imageguided instruments within this surgical field, requires a linear trajectory between the infrared camera, the reference arc, and the instruments. This direct line of sight requires appropriate placement of the infrared camera and the reference arc (Fig. 6). Incorrect reference arc positioning, as well as placement of objects that block the line of sight between the infrared camera and the reference arc, will result in line-of-sight issues with a resultant inability to navigate (Fig. 7A and B). Subsequently, time and frustration will be added to the case. The reference arc should always be placed between the camera and the area in the surgical field where the image-guided instruments are being used (Fig. 7C). In open cases, the reference arc is placed on the most superiorly exposed spinous process with the camera placed at the head of the bed. In minimally invasive cases in which a percutaneous reference arc is being used, the camera is placed at the foot of the bed as described above. The infrared camera has to be placed at an optimal distance from the reference arc, and the image-guided system has a function that will guide the OR staff in accomplishing this task. Direct light (overhead lights, head lights) shining on the reference arc will affect its ability to reflect the infrared light back to the camera and result in the inability to navigate..$^{19,20,31,39}$ If the line of sight is clear between the camera, the reference arc, and the instruments, and the image-guided system still does not visualize the image-guided instruments or reference arc, then the most likely cause is blood or other debris on the reflective spheres of the reference arc and/or imageguided instruments. In this scenario, the spheres should be cleaned with a wet towel or gauze pad and then dried. Bending of the instruments after registration can be problematic because remote instrument tracking relies on the stiffness and nondeformity of surgical instruments. Instru-

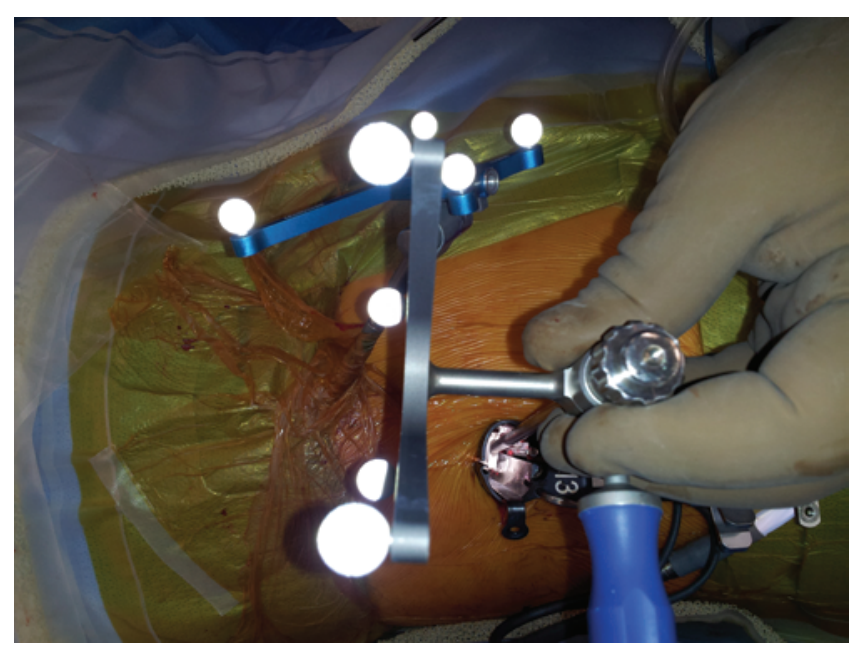

FIG. 5. Intraoperative photograph showing the reference arc inserted on the lateral iliac crest adjacent to the surgical site. The proximity of the arc to the surgical instruments results in errors while using image guidance and instrumentation. 


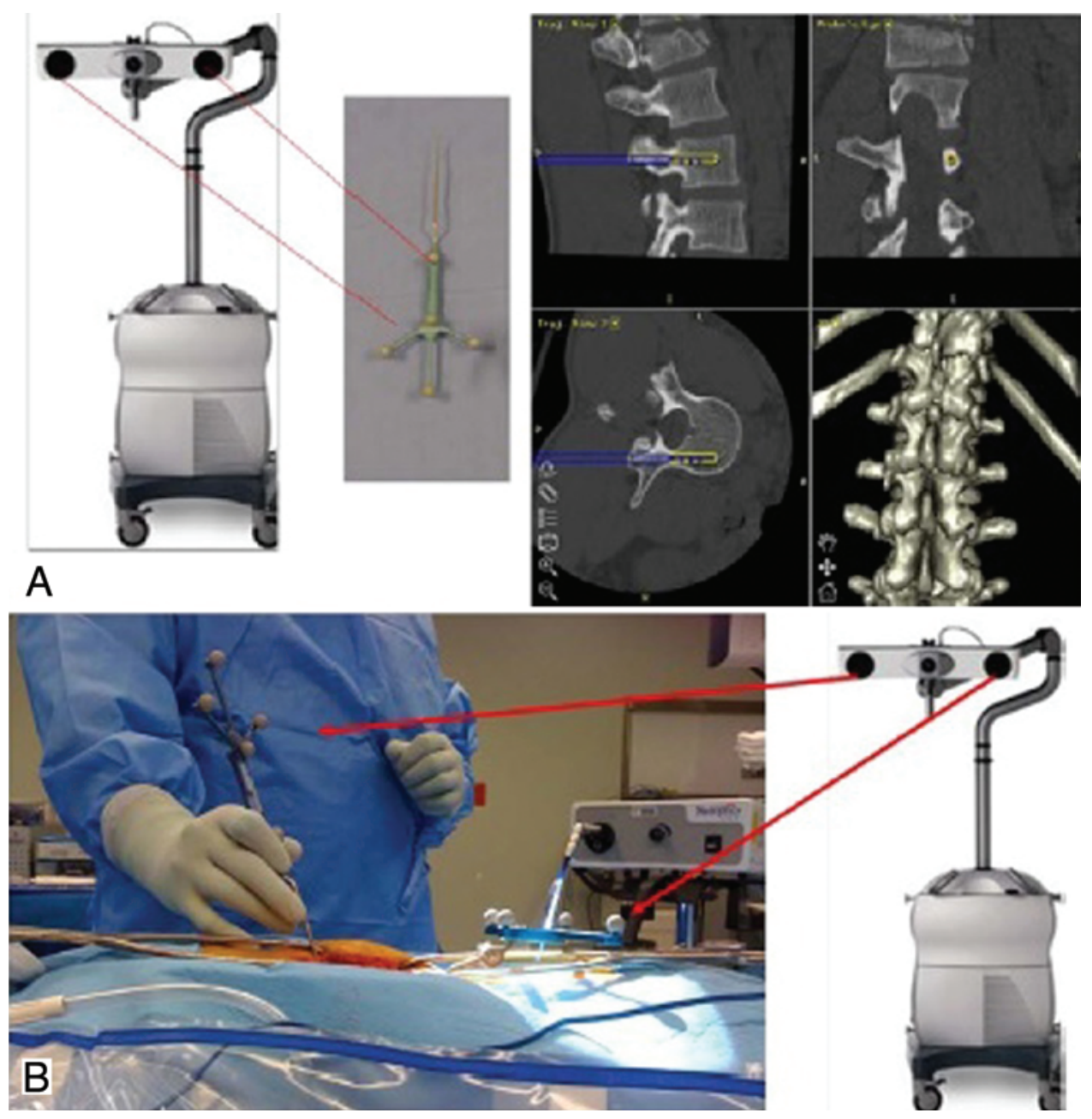

FIG. 6. Images showing the linear trajectory between the infrared camera, reference arc, and instruments. A: Image-guided systems (such as BrainLAB and StealthStation) with the camera using infrared light and reflecting spheres (shown on the instrument; left) are used to identify landmarks and instrument locations in the operating field and are visualized in 3 axes on the navigation monitor (right). B: The direct line of sight (noted as red lines between camera, reference arc, and surgical instruments) is essential for enabling accurate visualization, registering instruments, and identifying instrument position in relation to the corresponding surgical anatomy.

ments that are optically tracked and thin such as K-wires or drill bits could bend and result in inaccurate navigation. ${ }^{31}$ We have found that while using potentially flexible instruments it is vitally important to make sure that the surgeon does not bend the tool to correct the trajectory down the pedicle that is visualized on the image-guided system, as this deformity of the instrument gives the surgeon a false interpretation of instrument position on the image-guided system with resulting erroneous insertion of the implant.

\section{Wrong-Level Surgery}

Wrong-level surgery is another potential pitfall. The absence of visual anatomical landmarks, a steep learning curve, and tactile feedback readily available in open surgery, make the risks of wrong-level screw insertion higher with minimally invasive techniques. ${ }^{52}$ Our technique in these cases is to try to include the lumbosacral junction in lumbar cases to provide a point of reference. If the case involves the thoracic spine, then the reference arc placed on the spinous process serves as a marker to localize the appropriate level, and its location should be confirmed by counting levels from the lumbosacral junction using the fluoroscopy function on the cone-beam CT device prior to implementing the scan for cone-beam CT registration. Additionally, the reference arc should always be included in the cone-beam CT scan in these cases to always serve as a point of reference for confirmation of appropriate levels. During navigation, the image-guided platform will allow the field of view to be expanded for visualization of the lumbosacral junction and/or reference arc to confirm appropriate levels. Once appropriate levels are confirmed, the field of view can be zoomed in to allow better visualization of the spinal anatomy for instrumentation placement.

\section{Maintaining Navigation Accuracy}

Maintaining navigation accuracy following cone-beam CT registration must be constantly monitored throughout 


\section{Pitfalls in image-guided spinal navigation}

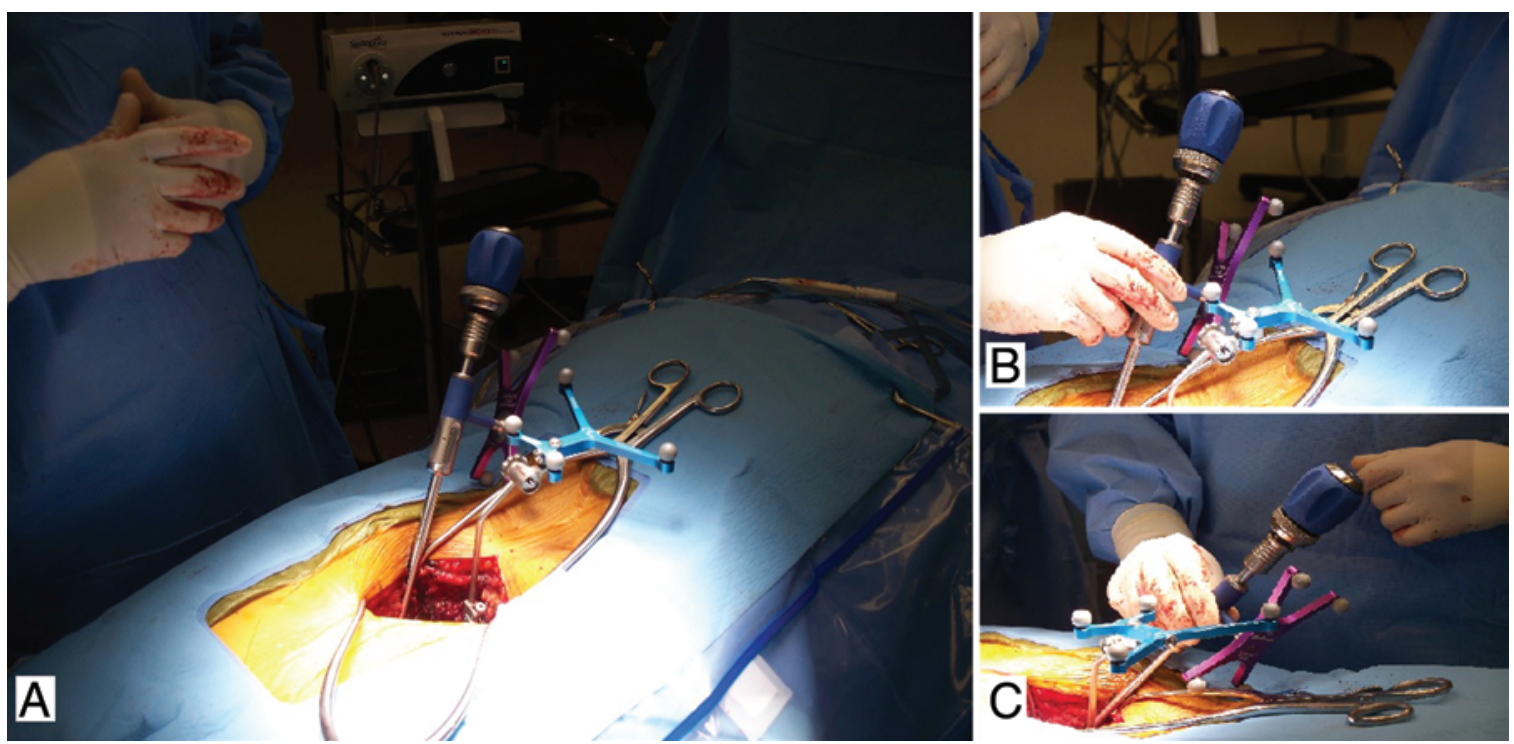

FIG. 7. Intraoperative photographs demonstrating positioning of the reference arc. A: Image showing the surgical field with the reference arc fixed on the spinous process at a level above the surgery site. B: The proximity of the instrument marker array with the reference arc could cause inadvertent collision and movement of the arc, as well as loss of image guidance, due to inability to track the instrument spheres. This can give rise to landmark inaccuracy, requiring the surgeon to maintain a high degree of procedural awareness. C: Simple maneuvers, such as manipulation of the surgical tools by rotating the instrument array away from the reference arc, avoids collisions, maintains accuracy, and provides accurate intraoperative landmarks.

the surgery. It is essential to firmly fixate the reference arc to the bone anatomy in lumbar and thoracic cases to ensure that the arc does not move relative to the patient's spine after cone-beam CT registration. In cervical cases, we attach the reference arc to the Mayfield head clamp. We believe the most stable reference fixation in the thoracolumbar spine occurs on the spinous process. It is important that the spikes on the clamp of the reference arc penetrate the cortical bone of the spinous process to prevent the clamp sliding on the bone. Interspinous placement of the reference arc has to be avoided. We gently pull on the reference arc after it is fixated, and before cone-beam CT registration, to confirm that fixation is secure. It is also important to apply counter traction on the reference arc stem when screwing the clamp onto the spinous process to prevent fracture of the spinous process. After cone-beam CT registration, it is essential that the surgeon and assistant do not bump the reference arc, which could move the arc relative to the patient's spine and result in navigation inaccuracy. Additionally, suction tubing and wires for the cauterization instruments should be positioned so that they do not contact or put traction on the arc when being used. At the skin level, placement of the reference arc at the apex of the incision should also be performed with caution if retractors are not in place at the time of reference arc placement, as retracting the wound will result in inferior movement of the incision apex resulting in applied force to the reference arc stem, which could result in movement of the reference arc relative to the spinal anatomy. Navigation accuracy is best immediately after cone-beam CT registration, so this is when instrumentation placement should occur. Complete exposure of the spine should be accomplished prior to cone-beam CT registration.

In long-level fusions, we still prefer reference arc placement on the most superiorly exposed spinous process. In these cases we will place instrumentation beginning distal to the arc and moving proximal, as instrumentation placement does result in some movement of the spine and the image-guided system is less accommodating in maintaining navigation accuracy at the levels most distal to the reference arc. As a result, the surgeon is moving closer to the reference arc with each subsequent level of screw placement in multilevel cases and this allows the image-guided system to better accommodate the spinal movement that occurs with instrumentation placement in multilevel fusion cases. Caution should be employed, however, in flexible spines (adolescent scoliosis and trauma cases) as the movement in the spine with instrumentation placement in these cases may supersede the ability of the image-guided system to accommodate for this movement, resulting in navigation inaccuracy. Furthermore, it is essential for the surgeon to confirm navigation accuracy prior to placement of each screw, which can be easily and quickly accomplished by touching the spine anatomy and confirming accuracy on the imageguided system. We typically use the transverse process for confirming navigation accuracy by quickly dragging the image-guided probe over the transverse process in the superior-inferior and medial-lateral planes. Avoiding excess force and torque on the spine will also help maintain navigation accuracy. In small or corticated pedicles, drilling the initial hole with an image-guided drill guide will prevent excessive banging of probes down the pedicle and the resulting movement of the spine associated with those maneuvers. Avoiding Trendelenburg and rotational changes in bed position after cone-beam $\mathrm{CT}$ registration will also help limit movement of the spine relative to the reference arc and will also help to maintain navigation accuracy in these long-level fusion procedures. 


\section{Postoperative Considerations}

\section{Radiation Exposure}

Minimizing radiation exposure to the staff and patient are essential components taken into account while using imaging guidance. Spinal instrumentation using active fluoroscopy remains cumbersome because of the necessity to maneuver around the fluoroscope while performing surgery and the need to use heavy protective lead shielding. ${ }^{25}$ Fluoroscopy can increase the radiation exposure to the surgeon by 10- to 12-fold in comparison with nonspinal procedures, and more so with complex multisegmental fusions, deformity corrections, and reoperations on the spine. ${ }^{45,50,70}$ With the use of low-dose helical CT techniques, a resulting 20-fold decrease has been noted in patients' radiation doses compared with standard CT. ${ }^{1-3}$ Nottmeier et al. demonstrated the absence of any radiation exposure to OR personnel using conebeam CT-guided imaging systems with absence of any radiation scatter if the surgeon stood more than 10 feet away from the system and behind a lead screen. ${ }^{40}$ It is important to keep in mind that the surgeon will perform a large number of these procedures in a year, whereas the patient may not require further imaging in the postoperative period once intraoperative imaging confirms appropriate implant insertion following surgery.

\section{Complication Rates}

Following the introduction of cone-beam CT-guided spinal navigation, numerous reports in the literature have been published demonstrating its utility in increasing the accuracy of pedicle screw placement and, at the same time, decreasing the incidence of neurological injury from misplaced pedicle screws. ${ }^{12,27,43,64,66}$ Scheufler et al. reported the accuracy of cervical $(99.3 \%)$, thoracic (97.8\%), and lumbar (94.4\%) pedicle-screw placement using CT-based neuronavigation systems. ${ }^{58,59}$ Silberman et al. compared freehand with navigation-guided pedicle screw insertion and found a breach rate of $5.9 \%$ with the freehand technique and a breach rate of $1 \%$ using navigation for lumbar screw placement. ${ }^{62}$ Several systematic reviews and meta-analyses comparing the accuracy of navigated versus nonnavigated pedicle-screw placement report that the pedicle-screw placements using navigation resulted in less pedicle breach ( $6 \%$ vs $15 \%$, respectively) as well as less neurological injury ( 3 vs 0 cases, respectively) ${ }^{60}$ Furthermore, Shin et al. found no statistically significant difference in operative time and estimated blood loss between navigated and nonnavigated cases. ${ }^{61}$ These publications support the use of image guidance in aiding surgeons in the placement of pedicle screws. Tow et al. recently published their results on accuracy of pedicle-screw placement using spinal navigation. ${ }^{69}$ They found a higher rate of misplaced screws $(37.5 \%)$ when the reference arc was placed more than 3 levels above their instrumentation level, and a rate of $13.89 \%$ when the arc was within 2 levels of their surgery. However, the importance of spinal navigation lies in its adjunct value to enhancing the accuracy of the spine surgeon in complex revision cases with distorted anatomy, and minimally invasive cases in which there is no landmark visualization.
Scheufler et al. found no statistically significant increase in misplaced screws when there was a 10 -segment difference between the instrumented segment and the reference $\operatorname{arc} .^{58}$ We have reviewed our data (unpublished) on pedicle-screw insertion greater than 5 levels from the reference arc and have not found increased rates of significant pedicle breach. The accuracy of pedicle screw placement is certain as long as there is no registration error and the surgeon finds no discrepancy between correlations of anatomical landmarks with corresponding image points. This concurs with the findings of Holly et al., who demonstrated navigation error as an interaction between technology and human factors..$^{18,67}$

\section{Cost-Effectiveness}

Various studies have shown that spinal navigation can be used without increasing OR time, and possibly with even shorter times compared with conventional surgery. ${ }^{49}$ Costa et al. evaluated the cost-effectiveness of intraoperative spinal navigation with preoperative planned navigation systems. ${ }^{9}$ In their study of hospital costs in patients with spondylolisthesis, they concluded that the two technologies were similar in cost. Despite these data, there may be a trend to suggest a cost advantage of using image-guided navigation in high-volume centers that specialize in more complex cases and perform more than 150 cases a year.

\section{Illustrative Case}

This 65-year-old woman presented with severe canal stenosis at the L4-5 levels with disc extrusion, degenerative changes, and moderate spondylolisthesis. She was symptomatic with neurogenic claudication and radiculopathy. She underwent a minimally invasive transforaminal lumbar interbody fusion. During the procedure there was movement in the reference arc, which was caused by either tugging by entangled suction tubes or inadvertent table movement after registration. While inserting 1 of the screws, tactile feedback felt incorrect and the angled trajectory seemed to be lateral, although it appeared appropriate on the imaging screen. On confirmatory imaging we found the pedicle screw was placed lateral and outside the pedicle (Fig. 8). We reregistered, found our starting point, tapped and reinserted the screw into the pedicle, and then confirmed this with imaging.

The authors present this case example to illustrate one of the key tenets of spine surgery with navigation. Surgeons must always be cognizant that the images on the screen are not shown in real time. Polyaxial screwdrivers will have some inherent movement at the instrument tip, and thinner-diameter taps may have some flexibility. Care must be taken to insert these tools as straight as possible so that the surgeon does not get "fooled" into thinking the implant is in the proper location when it actually is not.

\section{Discussion}

The absence of numerical data in the published literature makes it difficult to perform a systematic or meta- 


\section{Pitfalls in image-guided spinal navigation}

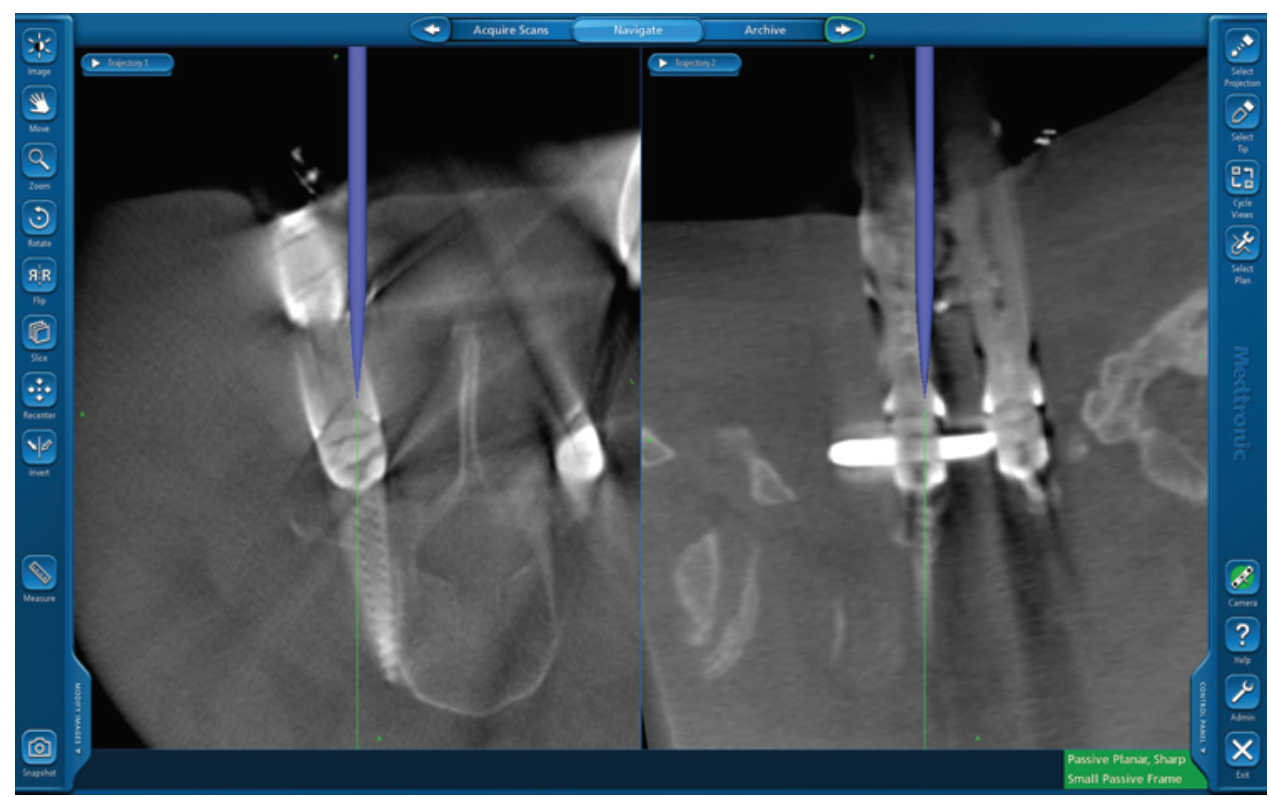

FIG. 8. Axial (left) and sagittal (right) cone-beam CT scans used for confirmation of pedicle screw positioning at the L4-5 levels following a minimally invasive transforaminal lumbar interbody fusion. In this image the pedicle screw has been placed lateral to the pedicle due to movement of the reference arc or operating table following image registration. This placement required reimaging and re-registration followed by correct repositioning of the misplaced pedicle screw. The sagittal image reveals the proximity of the $L-4$ and $L-5$ pedicles in the sagittal plane, making wrong-level insertions possible if the image is extremely magnified. Thus, we prefer larger fields of view for localization and initial drilling and pedicle tapping, followed by magnified imaging for final pedicle screw insertion.

analysis on this topic. However, we have summarized the key points that need to be taken into account to avoid potential errors with image-guided navigation using conebeam CT (Table 1). Integrating the above preoperative checklist system $^{48}$ and incorporating these steps while using cone-beam CT may help reduce the learning curve, avoid duplicating unwanted steps, achieve better preoperative planning, minimize the potential for misplaced pedicle screws, reduce OR time, and diminish radiation exposure by minimizing frequent intraoperative imaging.

The use of image-guided spinal navigation has been gradually increasing among the surgical spine community. A recent global survey on the use of computer-aided spine surgery by Härtl et al. provided interesting data on the use of spinal navigation. ${ }^{15}$ With numerous publications demonstrating the time effectiveness of imageguided surgery and the reduction of radiation exposure to OR personnel, the number of centers utilizing imaging guidance is gradually increasing. $7,15,40,57,68$ Although approximately $80 \%$ of the respondents in the survey of Härtl et al. were favorable to the use of spinal navigation, the cost, training, time efficiency, and integration into the OR workflow, as well as the lack of adequate training for surgeons, were cited as reasons for nonutilization of this technology ${ }^{40,42}$ There is a consensus among a majority of spine surgeons regarding the significant benefits when imaging guidance and navigation are used in minimally invasive spine surgery, deformity correction surgery, and revision spine cases in which the anatomical landmarks have been distorted.

The sources of potential error thus include imaging errors, surface model generation errors, tracking device fixation errors, registration errors, and inaccurate surgical tools or actions. Any of these alone or in combination result in cumulative errors. ${ }^{17,51}$ Zwingmann et al. performed a retrospective analysis using data from the German pelvic trauma registry and evaluated the intraoperative complications using navigated and conventional techniques for percutaneous iliosacral screw fixations in pelvic fractures. ${ }^{75}$ In this prospective multicenter study, they found a similar number of intraoperative and postoperative complications when comparing navigated and conventional techniques for percutaneous iliosacral screw fixation, but had a significantly higher rate of neurological complications. They could not analyze their data to identify the cause of higher neurological morbidity in the navigated group, but identified technical mistakes in the use of navigation or secondary dislocations as a cause of this increased morbidity. ${ }^{74}$

In a global survey by Härtl et al. regarding the use of navigation, only $11 \%$ of surgeons in North America and Europe used navigation in spite of its widespread availability. ${ }^{15}$ The users of navigation cited increasing accuracy, facilitating complex surgery, minimizing radiation exposure, performing a high volume of surgeries, and its use for minimally invasive surgeries as advantages. For the nonusers of navigation, the high cost of these systems, lack of adequate training, equipment issues, steep learning curve, and disruption of workflow were cited. In the survey these surgeons wanted valid data to prove precision, cost effectiveness, radiation exposure, and training to integrate workflow and technical issues associated with spinal navigation.

With an increasing number of intraoperative imaging 
TABLE 1: Summary of key points in cone-beam CT-based image-guided spine surgery

\begin{tabular}{|c|c|}
\hline Step & Key Points \\
\hline setup & $\begin{array}{l}\text { position camera to maximize line of sight } \\
\text { position monitor so easily visualized by surgeon } \\
\text { patient positioning } \\
\text { tuck patient's arms for mid- to high-thoracic \& cervical cases to allow positioning of cone-beam } \\
\text { CT device around patient } \\
\text { use radiolucent/Jackson table } \\
\text { Mayfield head clamp; radiolucent head clamp does not have to be used, but angle head clamp } \\
\text { superiorly out of the cone-beam CT field of view }\end{array}$ \\
\hline registration & $\begin{array}{l}\text { reference arc placement } \\
\text { firmly affix reference arc to spinous process or iliac crest } \\
\text { cone-beam CT registration } \\
\text { drape patient, not cone-beam CT device }\end{array}$ \\
\hline maintaining navigational accuracy & $\begin{array}{l}\text { perform cone-beam CT scan w/ retractors in place (cervical) } \\
\text { hold patient respirations during cone-beam CT scan } \\
\text { insert instrumentation immediately after registration } \\
\text { insert instrumentation starting at the most distal level from the arc \& work towards the arc } \\
\text { briefly check navigation accuracy on patient anatomy prior to placement of each screw } \\
\text { avoid changing Trendelenburg position of bed after registration } \\
\text { avoid excessive banging on instruments \& movement of spine } \\
\text { be aware of flexible spines (adolescent scoliosis patients \& trauma patients) } \\
\text { do not bump or adjust reference arc after cone-beam CT registration } \\
\text { do not bend image-guided instruments } \\
\text { always remember that the images on the screen are not in real time }\end{array}$ \\
\hline maintaining line of site & $\begin{array}{l}\text { place reference arc between the camera \& the working space for image-guided instruments } \\
\text { avoid placing objects (suction, clamps) in front of reference arc } \\
\text { avoid shining light (headlight, overhead lights) directly on reference arc }\end{array}$ \\
\hline computer-surgeon interface & $\begin{array}{l}\text { surgeon or qualified OR staff interfaces \& drives computer } \\
\text { consider intraoperative planning function of image-guided system during screw placement } \\
\text { helps to maximize screw size } \\
\text { helps to guide tapping of pedicle \& placement of screw down the pedicle to prevent pedicle breach }\end{array}$ \\
\hline confirming accurate instrumentation placement & perform cone-beam CT scan prior to leaving OR \\
\hline
\end{tabular}

and navigation options being made available to surgeons, integrating effective training and shortening the learning curve are essential to making this technique costeffective and safe. However, if the surgical team is aware and takes into account the above pitfalls, image-guided systems enable safe and accurate placement of spinal instrumentation in both routine and challenging situations.

\section{Conclusions}

Image-guided surgery and the tools associated with spinal navigation add a significant value to the armamentarium of the spine surgeon. Image-guided navigation cannot replace the technical expertise and training of spine surgeons, but is a useful adjunct to increasing the accuracy in training, and various complex surgical cases. Spine surgeons using this technology need to be aware of the pitfalls associated with the use of these systems and use good surgical judgment to achieve safe surgical outcomes.

\section{Disclosure}

Dr. Nottmeier has received speaking fees from Medtronic Navigation and BrainLAB, and serves as a consultant to K2M and Excelsius Surgical.
Author contributions to the study and manuscript preparation include the following. Conception and design: Rahmathulla, Nottmeier, Deen. Acquisition of data: Rahmathulla. Analysis and interpretation of data: Rahmathulla, Nottmeier, Pirris, Deen. Drafting the article: Rahmathulla, Nottmeier. Critically revising the article: all authors. Reviewed submitted version of manuscript: all authors. Approved the final version of the manuscript on behalf of all authors: Rahmathulla. Statistical analysis: Rahmathulla. Administrative/technical/material support: Pirris, Deen, Pichelmann. Study supervision: Pirris, Deen, Pichelmann.

\section{References}

1. Abul-Kasim K, Overgaard A, Maly P, Ohlin A, Gunnarsson M, Sundgren PC: Low-dose helical computed tomography (CT) in the perioperative workup of adolescent idiopathic scoliosis. Eur Radiol 19:610-618, 2009

2. Abul-Kasim K, Söderberg M, Selariu E, Gunnarsson M, Kherad M, Ohlin A: Optimization of radiation exposure and image quality of the cone-beam $\mathrm{O}$-arm intraoperative imaging system in spinal surgery. J Spinal Disord Tech 25:52-58, 2012

3. Abul-Kasim K, Strömbeck A, Ohlin A, Maly P, Sundgren PC: Reliability of low-radiation dose CT in the assessment of screw placement after posterior scoliosis surgery, evaluated with a new grading system. Spine (Phila Pa 1976) 34:941-948, 2009

4. Abumi K, Shono Y, Ito M, Taneichi H, Kotani Y, Kaneda K: Complications of pedicle screw fixation in reconstructive sur- 
gery of the cervical spine. Spine (Phila Pa 1976) 25:962-969, 2000

5. Amiot LP, Lang K, Putzier M, Zippel H, Labelle H: Comparative results between conventional and computer-assisted pedicle screw installation in the thoracic, lumbar, and sacral spine. Spine (Phila Pa 1976) 25:606-614, 2000

6. Bai YS, Zhang Y, Chen ZQ, Wang CF, Zhao YC, Shi ZC, et al: Learning curve of computer-assisted navigation system in spine surgery. Chin Med J (Engl) 123:2989-2994, 2010

7. Bandela JR, Jacob RP, Arreola M, Griglock TM, Bova F, Yang M: Use of CT-based intraoperative spinal navigation: management of radiation exposure to operator, staff, and patients. World Neurosurg 79:390-394, 2013

8. Brodwater BK, Roberts DW, Nakajima T, Friets EM, Strohbehn JW: Extracranial application of the frameless stereotactic operating microscope: experience with lumbar spine. Neurosurgery 32:209-213, 1993

9. Costa F, Cardia A, Ortolina A, Fabio G, Zerbi A, Fornari M: Spinal navigation: standard preoperative versus intraoperative computed tomography data set acquisition for computer-guidance system: radiological and clinical study in 100 consecutive patients. Spine (Phila Pa 1976) 36:2094-2098, 2011

10. Ebmeier K, Giest K, Kalff R: Intraoperative computerized tomography for improved accuracy of spinal navigation in pedicle screw placement of the thoracic spine. Acta Neurochir Suppl 85:105-113, 2003

11. Gebhard F, Weidner A, Liener UC, Stöckle U, Arand M: Navigation at the spine. Injury 35 (Suppl 1):35-45, 2004

12. Gelalis ID, Paschos NK, Pakos EE, Politis AN, Arnaoutoglou CM, Karageorgos AC, et al: Accuracy of pedicle screw placement: a systematic review of prospective in vivo studies comparing free hand, fluoroscopy guidance and navigation techniques. Eur Spine J 21:247-255, 2012

13. Girardi FP, Cammisa FP Jr, Sandhu HS, Alvarez L: The placement of lumbar pedicle screws using computerised stereotactic guidance. J Bone Joint Surg Br 81:825-829, 1999

14. Glossop ND, Hu RW, Randle JA: Computer-aided pedicle screw placement using frameless stereotaxis. Spine (Phila Pa 1976) 21:2026-2034, 1996

15. Härtl R, Lam KS, Wang J, Korge A, Kandziora F, Audigé L: Worldwide survey on the use of navigation in spine surgery. World Neurosurg 79:162-172, 2013

16. Heary RF, Bono CM, Black M: Thoracic pedicle screws: postoperative computerized tomography scanning assessment. J Neurosurg 100 (4 Suppl Spine):325-331, 2004

17. Helm PA, Eckel TS: Accuracy of registration methods in frameless stereotaxis. Comput Aided Surg 3:51-56, 1998

18. Holly LT, Bloch O, Johnson JP: Evaluation of registration techniques for spinal image guidance. J Neurosurg Spine 4: 323-328, 2006

19. Holly LT, Foley KT: Image guidance in spine surgery. Orthop Clin North Am 38:451-461, 2007

20. Holly LT, Foley KT: Intraoperative spinal navigation. Spine (Phila Pa 1976) 28 (15 Suppl):S54-S61, 2003

21. Hott JS, Deshmukh VR, Klopfenstein JD, Sonntag VKH, Dickman CA, Spetzler RF, et al: Intraoperative Iso-C C-arm navigation in craniospinal surgery: the first 60 cases. Neurosurgery 54:1131-1137, 2004

22. Ito Y, Sugimoto Y, Tomioka M, Hasegawa Y, Nakago K, Yagata Y: Clinical accuracy of 3D fluoroscopy-assisted cervical pedicle screw insertion. Clinical article. J Neurosurg Spine 9:450-453, 2008

23. Kalfas IH, Kormos DW, Murphy MA, McKenzie RL, Barnett GH, Bell GR, et al: Application of frameless stereotaxy to pedicle screw fixation of the spine. J Neurosurg 83:641-647, 1995

24. Kast E, Mohr K, Richter HP, Börm W: Complications of transpedicular screw fixation in the cervical spine. Eur Spine J 15:327-334, 2006
25. Kim CW, Lee YP, Taylor W, Oygar A, Kim WK: Use of navigation-assisted fluoroscopy to decrease radiation exposure during minimally invasive spine surgery. Spine J 8:584-590, 2008

26. Kim YJ, Lenke LG, Cho SK, Bridwell KH, Sides B, Blanke $\mathrm{K}$ : Comparative analysis of pedicle screw versus hook instrumentation in posterior spinal fusion of adolescent idiopathic scoliosis. Spine (Phila Pa 1976) 29:2040-2048, 2004

27. Kosmopoulos V, Schizas C: Pedicle screw placement accuracy: a meta-analysis. Spine (Phila Pa 1976) 32:E111-E120, 2007

28. Laine T, Lund T, Ylikoski M, Lohikoski J, Schlenzka D: Accuracy of pedicle screw insertion with and without computer assistance: a randomised controlled clinical study in 100 consecutive patients. Eur Spine J 9:235-240, 2000

29. Laine T, Mäkitalo K, Schlenzka D, Tallroth K, Poussa M, Alho A: Accuracy of pedicle screw insertion: a prospective CT study in 30 low back patients. Eur Spine J 6:402-405, 1997

30. Laine T, Schlenzka D, Mäkitalo K, Tallroth K, Nolte LP, Visarius H: Improved accuracy of pedicle screw insertion with computer-assisted surgery. A prospective clinical trial of 30 patients. Spine (Phila Pa 1976) 22:1254-1258, 1997

31. Langlotz F: Potential pitfalls of computer aided orthopedic surgery. Injury 35 (Suppl 1):17-23, 2004

32. Liljenqvist UR, Halm HF, Link TM: Pedicle screw instrumentation of the thoracic spine in idiopathic scoliosis. Spine (Phila Pa 1976) 22:2239-2245, 1997

33. Linhardt O, Perlick L, Lüring C, Stern U, Plitz W, Grifka J: [Extracorporeal single dose and radiographic dosage in imagecontrolled and fluoroscopic navigated pedicle screw implantation.] Z Orthop Ihre Grenzgeb 143:175-179, 2005 (Ger)

34. Mayer EK, Winkler MH, Aggarwal R, Karim O, Ogden C, Hrouda D, et al: Robotic prostatectomy: the first UK experience. Int J Med Robot 2:321-328, 2006

35. Merloz P, Tonetti J, Cinquin P, Lavallée S, Troccaz J, Pittet L: [Computer-assisted surgery: automated screw placement in the vertebral pedicle.] Chirurgie 123:482-490, 1998 (Fr)

36. National Heart, Lung, and Blood Institute, National Institute of Diabetes and Digestive and Kidney Diseases: Clinical Guidelines on the Identification, Evaluation, and Treatment of Overweight and Obesity in Adults: The Evidence Report. Bethesda, MD: National Institutes of Health, 1998

37. Neo EL, Zingg U, Devitt PG, Jamieson GG, Watson DI: Learning curve for laparoscopic repair of very large hiatal hernia. Surg Endosc 25:1775-1782, 2011

38. Nolte L, Zamorano L, Arm E, Visarius H, Jiang Z, Berlerman $\mathrm{U}$, et al: Image-guided computer-assisted spine surgery: a pilot study on pedicle screw fixation. Stereotact Funct Neurosurg 66:108-117, 1996

39. Nottmeier EW: A review of image-guided spinal surgery. J Neurosurg Sci 56:35-47, 2012

40. Nottmeier EW, Bowman C, Nelson KL: Surgeon radiation exposure in cone beam computed tomography-based, imageguided spinal surgery. Int J Med Robot 8:196-200, 2012

41. Nottmeier EW, Crosby T: Timing of vertebral registration in three-dimensional, fluoroscopy-based, image-guided spinal surgery. J Spinal Disord Tech 22:358-360, 2009

42. Nottmeier EW, Pirris SM, Edwards S, Kimes S, Bowman C, Nelson KL: Operating room radiation exposure in cone beam computed tomography-based, image-guided spinal surgery. Clinical article. J Neurosurg Spine 19:226-231, 2013

43. Nottmeier EW, Seemer W, Young PM: Placement of thoracolumbar pedicle screws using three-dimensional image guidance: experience in a large patient cohort. Clinical article. J Neurosurg Spine 10:33-39, 2009

44. Nottmeier EW, Young PM: Image-guided placement of occipitocervical instrumentation using a reference arc attached to the headholder. Neurosurgery 66 (3 Suppl Operative):138-142, 2010 
45. Perisinakis K, Theocharopoulos N, Damilakis J, Katonis $\mathrm{P}$, Papadokostakis G, Hadjipavlou A, et al: Estimation of patient dose and associated radiogenic risks from fluoroscopically guided pedicle screw insertion. Spine (Phila Pa 1976) 29: $1555-1560,2004$

46. Pirris SM, Nottmeier EW: A case series on the technical use of three-dimensional image guidance in subaxial anterior cervical surgery. Int $\mathbf{J}$ Med Robotics Comput Assist Surg [in press], 2014

47. Quiñones-Hinojosa A, Robert Kolen E, Jun P, Rosenberg WS, Weinstein PR: Accuracy over space and time of computerassisted fluoroscopic navigation in the lumbar spine in vivo. $\mathbf{J}$ Spinal Disord Tech 19:109-113, 2006

48. Rahmathulla G, Recinos PF, Traul DE, Avitsian R, Yunak M, Harper NT, et al: Surgical briefings, checklists, and the creation of an environment of safety in the neurosurgical intraoperative magnetic resonance imaging suite. Neurosurg Focus 33(5):E12, 2012

49. Rajasekaran S, Vidyadhara S, Ramesh P, Shetty AP: Randomized clinical study to compare the accuracy of navigated and non-navigated thoracic pedicle screws in deformity correction surgeries. Spine (Phila Pa 1976) 32:E56-E64, 2007

50. Rampersaud YR, Foley KT, Shen AC, Williams S, Solomito $\mathrm{M}$ : Radiation exposure to the spine surgeon during fluoroscopically assisted pedicle screw insertion. Spine (Phila Pa 1976) 25:2637-2645, 2000

51. Rampersaud YR, Simon DA, Foley KT: Accuracy requirements for image-guided spinal pedicle screw placement. Spine (Phila Pa 1976) 26:352-359, 2001

52. Ravi B, Zahrai A, Rampersaud R: Clinical accuracy of computer-assisted two-dimensional fluoroscopy for the percutaneous placement of lumbosacral pedicle screws. Spine (Phila Pa 1976) 36:84-91, 2011

53. Richter M, Cakir B, Schmidt R: Cervical pedicle screws: conventional versus computer-assisted placement of cannulated screws. Spine (Phila Pa 1976) 30:2280-2287, 2005

54. Rose PS, Lenke LG, Bridwell KH, Mulconrey DS, Cronen GA, Buchowski JM, et al: Pedicle screw instrumentation for adult idiopathic scoliosis: an improvement over hook/hybrid fixation. Spine (Phila Pa 1976) 34:852-858, 2009

55. Rosser JC Jr, Lynch PJ, Cuddihy L, Gentile DA, Klonsky J, Merrell R: The impact of video games on training surgeons in the 21st century. Arch Surg 142:181-186, 2007

56. Sasso RC, Garrido BJ: Computer-assisted spinal navigation versus serial radiography and operative time for posterior spinal fusion at L5-S1. J Spinal Disord Tech 20:118-122, 2007

57. Scheufler KM, Cyron D, Dohmen H, Eckardt A: Less invasive surgical correction of adult degenerative scoliosis, part I: technique and radiographic results. Neurosurgery 67:696710,2010

58. Scheufler KM, Franke J, Eckardt A, Dohmen H: Accuracy of image-guided pedicle screw placement using intraoperative computed tomography-based navigation with automated referencing, Part I: cervicothoracic spine. Neurosurgery 69:782-795, 2011

59. Scheufler KM, Franke J, Eckardt A, Dohmen H: Accuracy of image-guided pedicle screw placement using intraoperative computed tomography-based navigation with automated referencing. Part II: thoracolumbar spine. Neurosurgery 69:1307-1316, 2011

60. Shin BJ, James AR, Njoku IU, Härtl R: Pedicle screw navigation: a systematic review and meta-analysis of perforation risk for computer-navigated versus freehand insertion. A review. J Neurosurg Spine 17:113-122, 2012

61. Shin MH, Ryu KS, Park CK: Accuracy and safety in pedicle screw placement in the thoracic and lumbar spines: comparison study between conventional C-arm fluoroscopy and navigation coupled with O-arm ${ }^{\circledR}$ guided methods. J Korean Neurosurg Soc 52:204-209, 2012

62. Silbermann J, Riese F, Allam Y, Reichert T, Koeppert H, Gutberlet M: Computer tomography assessment of pedicle screw placement in lumbar and sacral spine: comparison between free-hand and $\mathrm{O}$-arm based navigation techniques. Eur Spine J 20:875-881, 2011

63. Simon DA, Lavallée S: Medical imaging and registration in computer assisted surgery. Clin Orthop Relat Res (354):1727, 1998

64. Tian NF, Huang QS, Zhou P, Zhou Y, Wu RK, Lou Y, et al: Pedicle screw insertion accuracy with different assisted methods: a systematic review and meta-analysis of comparative studies. Eur Spine J 20:846-859, 2011

65. Tian NF, Xu HZ: Image-guided pedicle screw insertion accuracy: a meta-analysis. Int Orthop 33:895-903, 2009

66. Tian W, Lang Z, Liu YJ, Liu B, Li Q, Hu L, et al: [Study of pedicle screw placement assisted by intraoperative three-dimensional navigation in lumbar vertebrae with axial rotation.] Zhonghua Wai Ke Za Zhi 48:838-841, 2010 (Chinese)

67. Tjardes T, Shafizadeh S, Rixen D, Paffrath T, Bouillon B, Steinhausen ES, et al: Image-guided spine surgery: state of the art and future directions. Eur Spine J 19:25-45, 2010

68. Tormenti MJ, Kostov DB, Gardner PA, Kanter AS, Spiro RM, Okonkwo DO: Intraoperative computed tomography imageguided navigation for posterior thoracolumbar spinal instrumentation in spinal deformity surgery. Neurosurg Focus 28(3):E11, 2010

69. Tow BP, Yue WM, Srivastava A, Lai JM, Guo CM, Peng BC, et al: Does navigation improve accuracy of placement of pedicle screws in single level lumbar degenerative spondylolisthesis? - A comparison between free-hand and 3D O-arm navigation techniques. J Spinal Disord Tech [epub ahead of print], 2013

70. U1 Haque M, Shufflebarger HL, O'Brien M, Macagno A: Radiation exposure during pedicle screw placement in adolescent idiopathic scoliosis: is fluoroscopy safe? Spine (Phila Pa 1976) 31:2516-2520, 2006

71. Vaccaro AR, Rizzolo SJ, Balderston RA, Allardyce TJ, Garfin SR, Dolinskas C, et al: Placement of pedicle screws in the thoracic spine. Part II: an anatomical and radiographic assessment. J Bone Joint Surg Am 77:1200-1206, 1995

72. Vaidya R, Carp J, Bartol S, Ouellette N, Lee S, Sethi A: Lumbar spine fusion in obese and morbidly obese patients. Spine (Phila Pa 1976) 34:495-500, 2009

73. Weinstein JN, Spratt KF, Spengler D, Brick C, Reid S: Spinal pedicle fixation: reliability and validity of roentgenogrambased assessment and surgical factors on successful screw placement. Spine (Phila Pa 1976) 13:1012-1018, 1988

74. Zwingmann J, Konrad G, Mehlhorn AT, Südkamp NP, Oberst M: Percutaneous iliosacral screw insertion: malpositioning and revision rate of screws with regards to application technique (navigated vs. conventional). J Trauma 69:1501-1506, 2010

75. Zwingmann J, Südkamp NP, König B, Culemann U, Pohlemann T, Aghayev E, et al: Intra- and postoperative complications of navigated and conventional techniques in percutaneous iliosacral screw fixation after pelvic fractures: results from the German Pelvic Trauma Registry. Injury 44:17651772,2013

Manuscript submitted November 15, 2013.

Accepted January 16, 2014.

Please include this information when citing this paper: DOI: 10.3171/2014.1.FOCUS13516.

Address correspondence to: Gazanfar Rahmathulla, M.D., Department of Neurosurgery, Mayo Clinic, 4500 San Pablo Rd., Cannaday 2E, Jacksonville, FL 32224. email: rahmathulla.gazanfar@mayo.edu. 